http://dx.doi.org/10.5007/2175-7968.2014v1n33p189

\title{
SIMMEL, TRADUÇÃO E AVENTURA
}

\author{
Antonio Carlos Santos* \\ Universidade do Sul de Santa Catarina
}

\begin{abstract}
Resumo: O objetivo deste ensaio é apresentar algumas ideias sobre a tradução dos textos de Georg Simmel, especialmente, a Filosofia do Dinheiro, e mostrar a importância do pensamento deste autor para uma reflexão sobre a teoria da modernidade.
\end{abstract}

Palavras-chave: Tradução. Simmel. Modernidade.

\section{SIMMEL, TRANSLATION AND ADVENTURE}

\begin{abstract}
The goal of this essay is to present some ideas about the translation of Georg Simmel's texts, specially the Philosophy of Money, and to show the importance of this author for a reflexion about a theory of the modern.
\end{abstract}

Keyword: Translation. Simmel. Modernity

Em seu texto Das Abenteuer (A aventura), Simmel (1983) define a aventura como aquilo que está em oposição aos encadeamentos dos círculos da vida, como um corpo estranho em nossa existência (ein Fremdkörper in unser Existenz) que, no entanto, está de alguma forma vinculado ao centro. É uma circunstância ou lance

* Possui graduação em Comunicação pelo Centro Unificado Profissional (1978), mestrado em Literatura pela Universidade Federal de Santa Catarina (1996) e doutorado em Literatura pela Universidade Federal de Santa Catarina (2001). Pós-doutorado em Teoria Literária, Universidade de São Paulo (USP), São Paulo, 2010. É tradutor e professor da Universidade do Sul de Santa Catarina (UNISUL). Florianópolis, Santa Catarina, Brasil. E-mail: caco1955@hotmail.com 
acidental que implica um certo risco, um perigo, que atravessa o contínuo da vida dando a ele uma coloração especial. Gostaria de comparar meu trabalho de tradução com os textos de Simmel com uma aventura. Comecei seduzido pelos pequenos textos, A ruína, incluído no mesmo livro A aventura, Philosophische Kultur (1983), Filosofia da Paisagem, A moda, entre outros. O que me fascinava neles era como Simmel deslocava todo o aparato da filosofia para alguns temas "menores", como bem reconheceu Adorno:

\begin{abstract}
Mas Georg Simmel [...], apesar de todo seu idealismo psicológico, foi o primeiro a efetuar o retorno da filosofia aos objetos concretos, uma mudança que se tornou canônica para todos aqueles que não estavam satisfeitos com o matraquear da epistemologia e da história do espírito (Geistesgeschichte). (ADORNO, 1994, p.558).
\end{abstract}

Simmel era um intelectual da virada do século XIX para o XX que sentia o esgotamento da filosofia tradicional, daí seu interesse por novos objetos, como a ponte, a moldura, a aventura, a ruína, a asa do jarro, a coqueteria, a paisagem, a moda, a conversa. Por seu caráter assistemático, Adorno comparou Benjamin ao mestre de quem havia seguido os cursos na Universidade de Berlim, no semestre de inverno de 1912-1913: "Seu esforço de retirar a filosofia do deserto gelado da abstração e inserir o pensamento em imagens históricas concretas é aparentado a Simmel, o antissistemático" (ADORNO, 1994, p. 571). Como diz Leopoldo Waizbort, a filosofia de Simmel encontra nos objetos concretos, nos fenômenos singulares, uma maneira de se renovar: "É em uma filosofia da aventura, do dinheiro, da paisagem ou do ator que ele encontra agora sua razão, e não mais na metafísica, ética ou teoria do conhecimento puras." (WAIZBORT, 2000, p. 33).

$\mathrm{Eu}$ estava pesquisando as imagens do final do século XIX, especialmente, as fotografias de Revert Henrique Klumb, Augusto 
Stahl, Juan Gutierrez, e os quadros da geração posterior a Pedro Américo e Victor Meirelles, de Belmiro de Almeida, Rodolfo Amoedo e Almeida Júnior, quando traduzi "O conceito e a tragédia da cultura", texto que também faz parte de Philosophische Kultur (SIMMEL, 1983). Neste ensaio, Simmel expõe sua ideia de uma tragédia da modernidade: se o processo cultural é uma dialética entre sujeito e objeto (entre espírito e natureza, vida e forma, fluxo contínuo e sua cristalização) cujo caminho vai do sujeito ao objeto, este compreendido como objetivação do espírito (sujeito), e, novamente, do objeto ao sujeito, ou seja, uma re-subjetivização do objeto com o objetivo de um aperfeiçoamento, de um cultivo da personalidade, aquilo que se costumava chamar de Bildung, para Simmel a tragédia da cultura reside no fato de que este objeto, que tem uma função mediadora no processo, que é um meio do espírito, espírito objetivado, para atingir um fim que é sempre o sujeito, ganha no transcurso da modernidade uma autonomia - de alguma forma essa autonomia já existe em sua estrutura - que acaba por fazer dele próprio o fim dessa cadeia de relações (sujeito/objeto/sujeito). Pois bem, me interessava seguir essa teoria da modernidade cuja tragédia é a transformação descontrolada dos meios em fins, a preponderância do objeto sobre o sujeito.

Por essa razão resolvi traduzir, sob a supervisão do professor Leopoldo Waizbort, a Filosofia do Dinheiro. Reuni as traduções inglesa, de Tom Bottomore (SIMMEL, 2004) e David Frisby, francesa, de Sabine Cornille e Philippe Ivernel (SIMMEL, 1999), e italiana, de Alessandro Cavalli, Renate Liebhart e Lucio Perucchi, (SIMMEL, 1998) comecei a trabalhar no texto. Escrita em forma de ensaio, forma capital na Alemanha moderna do século XIX, a Philosophie des Geldes (SIMMEL, 2001) tem seis capítulos, cada qual dividido em três partes, sendo o primeiro "Wert und Geld" (Valor e Dinheiro), o segundo "Der Substanzwert des Geldes" (O valor de substância do dinheiro), o terceiro "Das Geld in den Zweckreihen" (O dinheiro na série dos fins), o quarto "Die individuelle Freiheit" (A liberdade individual), o quinto "Das Geldäquivalent 
personaler Werte" (O equivalente monetário de valores pessoais) e o sexto "Der Stil des Lebens" (O estilo de vida). Está dividida em uma primeira parte analítica, que consiste em compreender a essência do dinheiro a partir das condições e relações da vida em geral, e uma parte sintética que, inversamente, parte da atuação do dinheiro para compreender a essência e configuração da vida. Publicado em 1900, ou seja, no mesmo ano da Traumdeutung, de Freud, e da morte de Nietzsche, este complexo de ensaios é ainda a confluência de uma série de outros textos que aparecem antes como Zur Psychologie des Geldes, de 1889, Einiges über die Prostitution in Gegenwart und Zukunft, de 1892, Zur Psychologie der Mode. Soziologische Studie, de 1895, Das Geld in der modernen Kultur, de 1896, Soziologische Ästhetik, de 1896, Die Bedeutung des Geldes für das Tempo des Lebens, de 1897, Über Geiz, Verschwendung und Armut, de 1899, Persönlische und sachlische Kultur, de 1900. O centro da reflexão simmeliana é a teoria do moderno, no entanto, como nos chama atenção Leopoldo Waizbort, esta teoria do moderno só pode ser entendida enquanto articulada a um diagnóstico do presente e a uma filosofia da cultura:

\begin{abstract}
[...] é interessante marcar esses três momentos, para que se possa ter uma dimensão mais clara da riqueza e multiplicidade das análises. $\mathrm{O}$ fato de que a atitude que Simmel defende para si compreenda estas três dimensões é por si mesmo significativo. Significa que qualquer uma das três, por si só, não lhe parece mais suficiente. (WAIZBORT, 2000, p.133)
\end{abstract}

É a mobilidade entre essas três pontas que faz a riqueza e o sabor especial dos ensaios de Simmel, mobilidade que é também um traço do ensaio, do moderno e da aventura. O que Jürgen Habermas critica nele, ou seja, o fato de ser um "pensador criativo mas não um pensador sistemático"1 (SIMMEL, 1983) é exatamente o 
que faz dele um teórico fundamental para o tempo presente, fundamental, ainda, para que se possa compreender melhor as linhas que passam pela reflexão de Walter Benjamin - basta comparar os temas com que Benjamin trabalhava em seu Passagenwerk, por exemplo -, de Theodor Adorno ou mesmo por um romance central da literatura de língua alemã como Der Mann ohne Eigenschaft ( $O$ homem sem qualidades), de Robert Musil. O diagnóstico equivocado de Habermas, assim como de outro aluno de Simmel, Georg Lukács, não diminui em nada a importância do livre pensador de Berlim, apenas confirma mais uma dessas ironias da história: enquanto a sistematicidade de pensadores como Habermas e Lukács parece cada vez mais distante dos tempos presentes, os ensaios de Simmel ganham potência como estímulos para que se possa pensar aquilo que Foucault, a partir de Kant, chamou de "ontologia do presente" (FOUCAULT, 1994, p. 679).

A Filosofia do Dinheiro gira em torno da relação entre os fins e os meios, ou seja, nas palavras de Waizbort (2000), "entre fins estipulados e determinados e os meios que são utilizados para a obtenção desses fins", como pode ser visto em Zur Psychologie des Geldes, texto que, ainda segundo Waizbort, "traz in nuce, de forma obviamente condensada e não desenvolvida, o texto de 1900 e, mais do que isso, delineia tópicos e problemas que perpassam toda a obra de Simmel". Simmel caracteriza essa relação com os fins como "construção teleológica", lembrando que essa relação é indireta. Articula, então, as finalidades às causas, pois aprofundar a consciência dos fins é aprofundar a consciência das causas, para, em seguida, ligar esse argumento à definição de cultura, entendida exatamente como o aprofundamento dos fins e das causas. Assim, o grau de cultura está relacionado à maneira com que o ser humano realiza seus fins: quanto mais "cultivado", maior a cadeia que separa os meios dos fins e por isso, nesse caso, enquanto um grau de cultura menos cultivado remete ao indivíduo singular, um estágio mais "adiantado" implica um "espírito público", pois o processo da cultura subentende um processo de diferenciação. Passando 
de uma análise geral, para uma análise econômica, Simmel chega então ao dinheiro, forma mediadora essencial, concentrando-se nos efeitos do dinheiro na psique humana - daí, nesse primeiro momento, a psicologia que depois evoluirá para uma filosofia; o mesmo acontece, por exemplo, com os textos sobre a moda, em 1895, Zur Psychologie der Mode, Soziologische Studie, e em 1905, Philosophie der Mode. O próximo passo, fundamental para a análise simmeliana, é perceber a transformação de um meio em um fim e sua consequente autonomização: “A autonomização dos meios frente aos fins que lhe davam sentido é o fato fundamental apresentado por Simmel". (WAIZBORT, 2000, p. 138) O exemplo maior dessa transformação e autonomização dos meios é, exatamente, o dinheiro, "um caso único e candente no conjunto de todas as transformações de meios em fins" (WAIZBORT, 2000, p. 139). Em Zur Psychologie des Geldes, Simmel (2001) trata de seguir um duplo movimento, ainda segundo a exposição de Waizbort: perceber o processo que faz do dinheiro um caso único de transformação de meios em fins na consciência e, ao mesmo tempo, analisar os efeitos do dinheiro sobre essa mesma consciência. É esse duplo movimento que Simmel explicará mais claramente na Philosophie des Geldes: "[...] pois então as partes "sintética" e "analítica", nas quais o livro se divide, têm por objetivo analisar o dinheiro a partir das condições da vida, e a vida a partir dos efeitos do dinheiro" (SIMMEL, 2001, p.140).

Minha tradução tem como diretiva o procedimento simmeliano de não só não separar função ou processo e conteúdo, mas de dar especial atenção ao processo, tal como o próprio pensador alemão explica no prefácio a Philosophische Kultu (trecho traduzido por Waizbort):

$\mathrm{Na}$ medida em que as afirmações filosóficas repousam distantes e incompatíveis entre si e não possuem uma validade inconteste por elas mesmas; na medida em que, não obstante, algo de comum é perceptível nelas, cujo valor sobrevive 
a toda contestação das afirmações singulares e suporta mais e mais o processo filosófico, aquilo de comum não pode estar em um conteúdo qualquer, mas somente neste processo mesmo. (WAIZBORT, 2000).

E seguindo, também, o objetivo de Leopoldo Waizbort (2000) em As aventuras de Georg Simmel de privilegiar o procedimento, sob o argumento de que o processo afeta os resultados: "[...] trata-se de uma leitura de sua Obra que privilegie o seu próprio modo de análise, e que somente a partir de seu procedimento se debruce sobre seus conteúdos". Desta forma, Simmel parece fugir uma vez mais da filosofia tradicional, na medida em que, se a literatura tem como traço fundamental um dobrar-se sobre o significante, ou, em outra palavras, uma atenção maior a seu próprio procedimento, em vez de fixar-se nos conteúdos, ou seja, o como é mais importante do que o que, o próprio da filosofia seria tornar o significante o mais transparente possível, focando sua atenção no significado. Não é à toa que Nietzsche, um filósofo tão assistemático quanto Simmel, é tantas vezes descartado por alguns setores mais conservadores da filosofia como "literatura": um texto como Also sprach Zarathustra desafia exatamente as fronteiras de uma filosofia que finge não ser escrita (écriture).

As dificuldades de um empreendimento como esse, a tradução da Filosofia do Dinheiro, assim como de outros textos do autor, não está apenas nas questões de terminologia, por si só já bastante complexas, mas na própria dinâmica do texto simmeliano, sempre sinuoso, com uma pontuação muito peculiar e uma sintaxe "barroca", repleta de analogias, excessiva a ponto de fazer, por exemplo, com que os tradutores para a língua inglesa cortem suas longas frases e fujam das complexidades de seus sintagmas nomimais, produzindo um texto "pragmático", mas bem pouco simmeliano (Cf. por exemplo, Essays on Religion, (SIMMEL, 1997)) publicado por Yale University, tradução de Horst Jürgen Helle com a colaboração de Ludwieg Nieder.) No caso desta tradução americana, temos 
um exemplo do que Antoine Berman chamou de "tradução etnocêntrica": "Partir do pressuposto que a tradução é a captação do sentido, é separá-lo de sua letra, de seu corpo mortal, de sua casca terrestre. É optar pelo universal e deixar o particular" (BERMAN, 2007, p. 32). Em outro trecho, Berman elenca algumas tendências deformadoras da tradução cujo objetivo é a destruição da "letra dos originais" em benefício do "sentido", entre eles, a racionalização:

\begin{abstract}
A racionalização diz respeito em primeiro lugar às estruturas sintáticas do original, bem como a este elemento delicado do texto em prosa que é a pontuação. A racionalização recompõe as frases e seqüências de frases de maneira a arrumálas conforme uma certa idéia de ordem de um discurso. (...) A racionalização conduz violentamente o original de sua arborescência à linearidade. (BERMAN, 2007, p. 48).
\end{abstract}

$\mathrm{Na}$ introdução aos Essays on religion (SIMMEL, 1997), Horst Jürgen Helle conta as dificuldades da tradução e a necessidade de cortar as longas frases do autor: "Leonard Broom, o primeiro a ler a tradução completa, nos fez ver a necessidade de fazer das longas frases de Simmel duas ou três frases mais controláveis em inglês". É interessante perceber a mesma intenção na tradução inglesa da "Filosofia do Dinheiro": "A edição alemã original aparece sem subtítulos no texto e sem um índice. Como quase nenhum escritor é citado no texto e como Simmel forneceu um sumário anotado, decidimos inserir essas anotações, sempre que possível, no corpo do texto tanto para quebrar de alguma forma a natureza monolítica da prosa de Simmel e para servir como um substituto do índice. Eventualmente, também, os parágrafos de Simmel foram quebrados em unidades menores". Poderíamos creditar essa estratégia de tradução à tentativa de tornar mais palatável o texto sinuoso de Simmel aos leitores de língua inglesa, o que não acontece, por exemplo, na tradução francesa. 
Meu desafio, portanto, foi buscar a letra de Simmel seguindo o mais de perto possível seu estilo sinuoso, difícil, sem subestimar o leitor e sem esquecer que não há uma divisão entre sentido e forma.

\section{Nota}

1. “(...) ist Simmel eher Anreger als Systematiker gewesen (...). Cf "Simmel als Zeitdiagnostiker” in Simmel, Georg (1983).

\section{Referências}

ADORNO, Theodor. Noten zur Literatur. Frankfurt am Main: Suhrkamp, 1994.

BERMAN, Antoine. A tradução e a letra ou o albergue do longínquo. Trad. Marie-Hélène Catherine Torres, Mauri Furlan e Andréia Guerini. Rio de Janeiro: Sete Letras, 2007.

FOUCAULT, Michel. Qu'est-ce que les Lumières. In: Dits et Écrits. 1954-1988. volume 1980-1988. Paris: Gallimard, 1994.

SIMMEL, Georg. Philosophische Kultur. Über das Abenteuer, die Geschlechter und die Krise der Moderne. Gesammelte Essais. Mit einem Nachwort von Jürgen Habermas. Berlin: Verlag Klaus Wagenbach, 1983.

. Essays on religion. Edited and translated by Horst Jürgen Helle in collaboration with Ludwig Nieder. New Haven: Yale University, 1997 
SIMMEL, Georg. Philosophie des Geldes. Frankfurt am Main: Suhrkamp Taschenbuch, 2001.

. Filosofia Del denaro. A cura di Alessandro Cavalli e Lucio Perucchi. Torino: Unione Tipografico-Editrice Torinese, 1998

. Philosophie de l'argent. Trad. Sabine Cornille e Philippe Ivernel. coll. Quadrige, Paris: PUF, 1999.

. The Philosophy of Money. Third enlarged edition. Tanslated by Tom Bottomore e David Frisby. Abingdon: Routledge, 2004.

WAIZBORT, Leopoldo. As aventuras de Georg Simmel. São Paulo: Editora 34: Coedição: Programa de Pós-Graduação em Sociologia da USP, 2000.

Recebido em: 17/09/2013

Aceito em: 02/01/2014 